\section{Políticas de Planejamento Urbano em Campinas: um estudo de caso sobre o bairro Cidade Satélite Íris.}

Urban Planning Policies in Campinas: a case study about Cidade Satélite líris Neighborhood.

Pedro Copola*, Cristina de Campos**

*Bacharel em Geografia pela Universidade Estadual de Campinas (UNICAMP) - 2017. Membro do NuPHiTT - Núcleo de Pesquisa em História, Território e Tecnologia Unicamp, ppccgeo@gmail.com

${ }^{* *}$ Doutora em Arquitetura e Urbanismo pela FAUUSP. Professora do Programa de Pós-Graduação em Arquitetura e Urbanismo Universidade São Judas Tadeu. Professora Colaboradora Programa de Pós-Graduação em Política Científica e Tecnológica do Instituto de Geociências da Universidade Estadual de Campinas, cristina.campos@saojudas.br

\section{Palavras-chave:}

Planejamento Urbano.

Campinas.

Cidade Satélite Íris.

Poder Público

\section{Keywords:}

Urban planning

Campinas.

Cidade Satélite Íris.

Public Authority.

\begin{abstract}
Resumo
blico Municipal espaço marcado pela luta de classes, onde o Poder Pú-

balho aqui proposto faz uso da abordagem dialética marxista como fer-

ramenta para interpretar a realidade urbana local, considerando-se sem-

pre o espaço urbano como um meio em constante transformação. $O$

objetivo é entender de que maneira as principais Políticas de Planeja-

mento Urbano engendradas pelo Poder Público Municipal de Campinas

contribuíram e contribuem para a produção do espaço urbano. Toma-se

como base para este estudo o caso do bairro Cidade Satélite Iris, locali-

dos piores índices de desenvolvimento humano.
\end{abstract} in the city. usjt

\section{arq.urb}

número 30 |jan-abr de 2021

Recebido: 21/05/2020

Aceito: 15/12/2020

DOI: $10.37916 /$ arq. urb.vi30.437

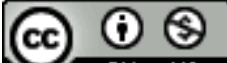

The city is a space characterized by the class conflict, where the Municipal Public Authority acts as regulator or mediator of this conflict. The work proposed here makes use of the Marxist dialectic as an interpreation tool of the local urban reality, always considering the urban space as an environment that is constantly changing. The aim is to understand in what way the main urban planning policies set up by the Municipa Public Authority of Campinas contributed and still contributes to the production of the urban space. This study is based on the case of the $\mathrm{Ci}$ dade Satélite Iris neighborhood, located at the northwest region of Campinas, and presenting one of the worst human development indices 


\section{Introdução}

O bairro Cidade Satélite Íris, localizado na região noroeste do município de Campinas, constantemente está presente em uma indigesta lista de bairros que apresentam os piores índices de desenvolvimento, nas mais diversas categorias de análise. Um estudo promovido pelo Programa das Nações Unidas (PNUD), em parceria com o Instituto de Pesquisa Econômica Aplicada (Ipea), com base no Censo de 2010 do IBGE, apontou que, o bairro contemplado neste estudo de caso está empatado com outras 12 áreas da cidade, com o pior índice de desenvolvimento humano do município, considerando fatores como renda, educação e longevidade.

Os elementos apontados são apenas alguns, dentre tantos outros, que demonstraram impressionante vulnerabilidade do local, por conseguinte, servindo de estopim para a escolha da localidade como palco do estudo de caso. Porém, não é pretensão deste artigo trabalhar esses elementos em profundidade, por mais que eles estejam em grande parte do tempo intrínsecos à discussão. O escopo do presente trabalho é o planejamento urbano.

O estudo do planejamento urbano contido neste trabalho compreende a cidade como um espaço eminentemente marcado pela luta de classes, onde o Poder Público Municipal atua como regulador ou mediador dessa disputa, devendo tal postura se realizar na práxis na forma de políticas urbanas. Trata-se, portanto, de um estudo que utiliza a análise marxista da cidade e do planejamento urbano como ferramenta para a interpretação da realidade urbana local, considerando-se sempre o espaço urbano como um meio em constante transformação, tal como o fazem o Arquiteto Flávio Villaça e a Socióloga Fabíola Rodrigues, as principais referências para o presente trabalho.

Desta forma, o objetivo do presente artigo é apresentar de que maneira as principais Políticas de Planejamento Urbano engendradas pelo Poder Público Municipal ao longo do tempo, contribuíram e vem contribuindo para a produção do espaço urbano, tal qual se observa no caso do bairro Cidade Satélite íris.

$\mathrm{O}$ artigo foi estruturado em cinco partes. A primeira apresenta a evolução da conjuntura socioeconômica e dos aspectos urbanos do município desde 1880 - marco estabelecido para o início da análise, em função da eclosão de graves surtos de febre amarela - até a década de 1930, quando se deu a promulgação do primeiro plano urbanístico do município.

As segunda, terceira e quarta partes abrangem um estudo do Planejamento Urbano local no âmbito dos planos urbanísticos, perpassando o Plano de Melhoramentos Urbanos de Prestes Maia em 1938 e o Plano Preliminar de Desenvolvimento Integrado em 1971, nas segundas e terceira partes respectivamente, e na quarta, os Planos Diretores de 1991, 1996 e 2006, logo após a promulgação da Constituição Federal de 1988.

A quinta parte apresenta os resultados sobre o estudo do bairro Cidade Satélite Íris, apresentando como surgiu e se desenvolveu historicamente, bem como sua interação com diferentes conjunturas socioeconômicas, políticas e urbanas. Por fim, as considerações finais apresentam um balanço final, observando como os Planos Diretores

\section{A evolução socioeconômica e urbana de Campinas rumo ao primeiro plano de ordenamento urbano}

Conquanto o primeiro plano de ordenamento urbano de Campinas tenha sido instituído em 1938, as ações voltadas ao planejamento urbano neste município tiveram início ainda no século XIX, principalmente em suas duas últimas décadas, e se estenderiam até a década de 1930 . Ainda que este projeto não tivesse galgado objetivos de grande amplitude, configurou-se como um marco para o entendimento da evolução urbana do município ao carregar consigo algumas particularidades.

Ao longo do período que compreende os últimos dois decênios do século XIX, Campinas esteve inserida em um contexto, onde a imigração europeia crescia de forma intensa, em consonância com uma ampla expansão da malha urbana, esta, atrelada diretamente à continuidade do processo de fortalecimento do complexo cafeeiro (CARVALHO, 1991; BADARÓ, 1996).

Porém, conquanto a economia cafeeira vivesse tempos de prosperidade, a população do centro urbano campineiro passava por um momento calamitoso. De acordo com Pavanati (2013), embora tenha havido investimentos do poder público local em obras de readequação, as condições de saneamento de grande parte da população mantiveram-se limitadas, permanecendo, portanto, um ambiente propício a eclosão de epidemias. 
Em 1889 Campinas foi acometida por um grave surto de febre amarela, aliás, o primeiro de três que ocorreriam até 1897. Na ocasião da ocorrência do primeiro surto Campinas apresentava uma população de 22.000 habitantes. Em 1896, de forma assustadora, a população foi reduzida para 5.000 habitantes. As únicas alternativas encontradas pelos habitantes foram a imediata busca por acolhida nas fazendas ou a mudança para outras cidades do interior pertencentes a regiões cafeeiras. Não menos expressiva foi a ida de campineiros à São Paulo, estes neste caso, atraídos por um cenário de intensa industrialização na capital da província (BATTISTONI FILHO, 1996; BADARÓ, 1996; CARVALHO, 1991).

Ao longo da década de 1890 uma série de medidas foi tomada por autoridades municipais visando a solução dos drásticos problemas decorrentes dos surtos de febre amarela. Pensando nas condições de salubridade a Intendência Municipal, em concordância com a Cia. Campineira de Águas e Esgotos ${ }^{1}$, decidiu implantar um serviço de água e esgoto, bem como retirar de imediato as cocheiras da região central da cidade e melhorar o serviço de coleta de lixo.

As leis $n^{\circ}-41$ e 43 dos anos de 1895 e 1896 estabeleceram normas de higiene e estética para as edificações urbanas. Uma série de exigências relacionadas à salubridade foi imposta, como áreas de ventilação e iluminação. Também exigia que todas as plantas produzidas deveriam obter aprovação prévia de um engenheiro municipal. Por fim, a cidade foi dividida em três distritos sanitários, onde delegados e inspetores pertencentes à Comissão de Higiene Municipal seriam responsáveis pela fiscalização (MARTINS, 2015; BADARÓ, 1996).

Novos esforços somaram-se às medidas já efetivadas pela Intendência Municipal. Ainda em 1896, após o último surto registrado, foram instaladas em Campinas a Comissão Sanitária do Estado de São Paulo, dirigida por Emílio Ribas e a Comissão de Saneamento, sob o comando do engenheiro Saturnino de Brito. Ambas foram fundamentais como propulsoras de um processo de recuperação da cidade em direção à uma retomada da prosperidade econômica tal qual no fim da década de 1880 (NUNES; PAVANATI, 2016).

${ }^{1}$ Foi fundada em 5 de junho de 1887, mas apenas no início da década de 1890 apresentou trabalho efetivo (LAPA, 1996; BADARÓ, 1996).
A partir do início do século XX Campinas já apresentava indícios de um retorno à normalidade. Em 1900 a população atingiu a marca de 19.000 habitantes, muito próximo dos 22.000 habitantes de 1889 quando se iniciou o primeiro surto de febre amarela. Porém, perdeu o posto de líder do desenvolvimento industrial no Estado. Entre 1900 e 1920 não houve uma implantação industrial de grande magnitude. No entanto, ao longo deste período, houve um amplo processo de acumulação dos capitais oriundos do café, preparando terreno para um desenvolvimento industrial mais expressivo que viria a ocorrer nas décadas de 1920 e 1930 (SEMEGHINI, 1988). Segundo Carvalho (1991), no ano de 1907 havia quatro grandes estabelecimentos fabris: Usina Esther, Tecelagem Carioba, Cia. Campineira de Carris de Ferro e a metalúrgica Cia. Mac Hardy. Os dois primeiros estavam localizados em territórios, que atualmente equivaleriam respectivamente aos municípios de Cosmópolis e Americana. Em 1908 e 1910 seriam instaladas, respectivamente, duas fábricas que viriam a adquirir grande expressividade, a Cervejaria Colúmbia e a Cia. Curtidora Campineira (BADARÓ, 1996).

A partir da década de 1910 predominou um processo de diversificação da agricultura. O destaque ficou por conta da cultura do algodão, em função da expansão da indústria têxtil, visando principalmente superar a migração dos principais cafezais para outras cidades do interior do Estado. Na década de 1920 fábricas importantes do setor foram instaladas em Campinas, como a Fábrica de Tecidos Elásticos Godoy e Valbert (1921), Fábrica de Seda Nossa Senhora Auxiliadora (1926) e a Sociedade Anônima Indústria de Seda Nacional (1926) (SEMEGHINI, 1988; BADARÓ, 1996).

Embora a década de 1930 carregue grande importância, em função de ter sido palco do início efetivo de um surto industrial, a década de 1920 pode ser considerada como um importante ponto de partida para a compreensão sobre o que ocorreria na década seguinte. É justamente neste período que se apresentou uma expressiva diversificação da indústria na cidade, possibilitando assim um revigoramento do complexo industrial local (CARVALHO, 1991).

“(...) a diversificação e expansão da agricultura e da indústria articulam-se com a rede urbana, fazendo desta uma imensa malha seletiva de atividades produtivas, 
bem como influenciando na distribuição da população, mobilizando-a em direção aos centros mais urbanizados" (CARVALHO, 1991, p. 34).

A vasta procura por terrenos na cidade em meados da década de 1920, em um cenário de franca expansão urbana, levou inevitavelmente à uma valorização dos mesmos. Portanto, de forma oportuna, neste período se instalaram em Campinas diversas empresas de loteamento. Era a especulação imobiliária adentrando a cena e já assumindo papel de destaque em uma nova configuração do território urbano local, esta como objeto de estudo do primeiro plano de ordenamento de Campinas, o Plano de Melhoramentos Urbanos de Prestes Maia (BADARÓ, 1996).

\section{O planejamento urbano em Campinas sob a alçada do Plano de Melhora- mentos Urbanos de Francisco Prestes Maia (1938-1970)}

O Plano de Melhoramentos Urbanos, aprovado através do Ato $\mathrm{n}^{\circ} 18$ de 23/04/1938, foi o primeiro plano de ordenamento urbano da cidade de Campinas, e também o mais longo em termos de vigência, tendo se estendido do final da década de 1930 até meados da década de 1960, quando cedeu espaço ao Plano Preliminar de Desenvolvimento Integrado.

Embora o Plano de Melhoramentos Urbanos tenha sido instituído oficialmente no final da década de 1930, sua concepção remonta a discussões ocorridas no final da década de 1920, que culminaram no envio de um ofício à Câmara Municipal - de autoria do Prefeito Orosimbo Maia (abr. 1926 - nov. 1930) - no ano de 1929, questionando a necessidade de ações de planejamento para a cidade naquele momento. O próprio prefeito tomou a iniciativa de contatar Luiz Ignácio Romeiro de Anhaia Mello, engenheiro e professor de urbanismo da Escola Politécnica de São Paulo, objetivando a criação de um plano para Campinas. O engenheiro, após visita à cidade, encaminhou um relatório propondo a realização de um Master Plañ para Campinas, porém, as conversas não seguiram adiante (BADARÓ, 1996; CARPINTERO, 1996).

${ }^{2}$ Este deveria obedecer a regulamentação estabelecida para a organização de planos para cidades, segundo a lei federal norte-americana Standard City Planning Enabling Act (KROGH; SALGADO, 2016).
Em 1933, durante a gestão do Prefeito Alberto de Cerqueira Lima (set. 1932 - dez. 1933), o engenheiro Carlos William Stevenson ministrou uma palestra cujo tema era o urbanismo, com destaque para a proposição de um plano viário para Campinas, baseado na obra Guide pratique de l'urbaniste do urbanista francês Jean Raymond. Tal acontecimento, segundo Badaró (1996), era claramente um prenúncio da contratação do engenheiro e arquiteto Francisco Prestes Maia no ano seguinte para a formulação do Plano de Melhoramentos Urbanos. Carpintero (1996) aponta como evidência o fato de Carlos W. Stevenson ter sido membro e presidente do Conselho Consultivo do Município ${ }^{3}$, enquanto que, no mesmo contexto, Badaró (1996) confirma ter havido prévios contatos entre Prestes Maia e Stevenson.

O ano de 1934 foi marcado por importantes acontecimentos na esfera do urbanismo em Campinas. A aprovação do Decreto no 76 de 16/03/1934 instituiu o Código de Construções, cuja função era regulamentar questões relacionadas a arruamentos e construções. No mês seguinte foram aprovadas as medidas para adução de água do Rio Atibaia e para ampliação das redes de água e de esgoto. Por fim, foi oficializada a contratação de Francisco Prestes Maia, que iniciaria a partir de então seus trabalhos, porém, efetivamente postos em prática apenas a partir de 1938 durante a gestão do Prefeito João Alves dos Santos (jun. 1936 - jul. 1938) (BADARÓ, 1996).

A aprovação do loteamento Jardim Chapadão através da Resolução no 977, de 1937, e a inauguração da Torre do Castelo em 1940, no mesmo local, foram acontecimentos bastante elucidativos do contexto político-econômico no qual esteve inserida a cidade naquele momento. Este, que definiria o início de um processo de desenvolvimento urbano nunca visto antes na história de Campinas (RODRIGUES, 2008).

A antiga Fazenda Chapadão, uma propriedade destinada à plantação de café, posteriormente transformada no loteamento Jardim Chapadão, ressalta o que Rodrigues (2008) denominou de um processo de conversão do capital agrário em capital

${ }^{3}$ Após a Revolução de 1930, o Governo Federal passou a intervir diretamente no âmbito municipal. Os prefeitos eram nomeados por um interventor federal no Estado de São Paulo e a Câmara Municipal foi substituída pelo Conselho Consultivo da Cidade, também definida pela mesma autoridade (BADARÓ, 1996). 
imobiliário, em um contexto de distensão do complexo cafeeiro. Ou seja, uma extensa área ocupada pelo café seria a partir de então transformada em área urbana 4 .

Conforme já fora registrado, a década de 1930 demonstrou ter sido palco de intenso crescimento do mercado imobiliário em Campinas, porém, a atuação desse setor seria impetuosa a partir da década de 1940, notadamente em concomitância à atuação não menos intensa do setor da construção civil. Naquele momento, houve um direcionamento explícito de ambos os setores para a implantação de núcleos de moradia popular. Segundo Rodrigues (2008), eram duas as motivações, sendo primeiramente a ampliação dos lucros do capital imobiliário e em segundo lugar uma estratégia de revalorização do centro, nitidamente galgada por intermédio da expulsão da população pobre que residia em habitações precárias no centro da cidade.

Desde 1945, quando se deu o fim da Segunda Guerra Mundial e também o fim do Estado Novo, o setor industrial se consolidou como o mais ativo da economia brasileira, repercutindo no contexto local em forma de novos processos urbanos. Neste período inúmeros estabelecimentos comerciais foram instalados na cidade, bem como edifícios públicos, e de forma marcante se deu o início da circulação das primeiras linhas de ônibus em 1949, conquanto os bondes elétricos ainda fossem o principal meio de transporte utilizado pela população da cidade (CARPINTERO, 1996).

Na transição para a década de 1950 tomaram grande ímpeto os processos de extensão e renovação urbanas, estes que ocorreram de forma articulada. Enquanto grandes porções centrais eram destruídas, visando a remodelação, em função de um projeto de desenvolvimento urbano, inúmeros empreendimentos eram iniciados em locais mais distantes do centro, como foram os casos da extensão do Cambuí, do Taquaral, do Botafogo e do Guanabara. Neste meio tempo a indústria continuou se afirmando em território campineiro, com destaque para a inauguração de indústrias de grande porte, como a Swift, a Dunlop e a Singer (BADARÓ, 1996; CARPINTERO, 1996).

${ }^{4}$ Rodrigues (2008) é enfática ao afirmar que essa inversão de capitais somente foi possível por intermédio de apoio do Poder Público.

${ }^{5}$ Segundo Badaró (1996), antes do início da segunda fase de implantação do Plano de Melhoramentos Urbanos foi criada a Comissão de Planejamento do Município, através da Lei no 1184 de agosto
Em 1951 a prefeitura realizou uma revisão das diretrizes propostas pelo Plano de Melhoramentos Urbanos, tendo sido aprovada pela Lei no 640 , de 28/12/1951, nos últimos dias de mandato do prefeito Arlindo Joaquim de Lemos Júnior (mai. 1951 dez. 1951), que havia substituído Miguel Vicente Cury (jan. 1948 - mai. 1951) após este renunciar ao cargo de prefeito para se candidatar a vereador. Segundo Carpintero (1996), a gestão seguinte, do prefeito Antônio Mendonça de Barros (jan. 1952 - dez. 1955) foi bastante acanhada no que tange a renovação urbana do centro da cidade, levando o autor ainda a dizer que a segunda etapa de implementação do Plano de Melhoramentos Urbanos só ocorreria efetivamente a partir de 1956, com o início da gestão do prefeito Ruy Hellmeister Novaes (jan. 1956 - jan. 1959).

A Posse do prefeito Ruy Novaes em 1956 ficou nitidamente marcada como a segunda fase de implantação do Plano de Melhoramentos Urbanos ${ }^{5}$. Naquele momento, o centro de Campinas havia se tornado um grande palco de obras. Entre os anos de 1956 e 1957 foram concluídas as obras de alargamento das Avenidas Francisco Glicério e Campos Sales, das ruas General Osório e Conceição bem como a demolição da Igreja do Rosário para a remodelação do Largo do Rosário (Figura 1) (BADARÓ, 1996).

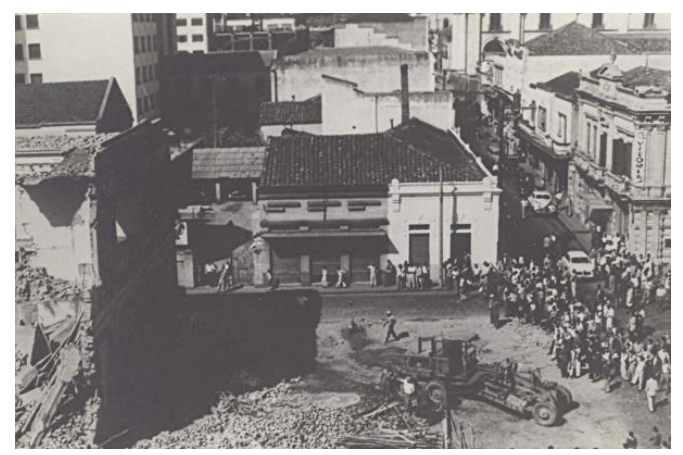

Figura 1: Transeuntes observam a demolição da Igreja do Rosário, no Largo do Rosário, no Centro de Campinas em 1956. Fonte: Acervo do Museu da Imagem e do Som de Campinas Col. Maria Luiza

de 1954, cuja função, de discutir os problemas urbanos de Campinas, seria propulsora de uma importante interação entre prefeitura, Câmara Municipal e outras entidades especialistas no assunto. 
O Plano de Melhoramentos Urbanos permaneceu efetivo até 1962, em meio ao segundo mandato do prefeito Miguel Vicente Cury (jan. 1960 - dez. 1963). Houve tempo ainda de realizar obras importantes, como a abertura das avenidas Moraes Salles e Senador Saraiva, tendo sido justamente no cruzamento de ambas que se deu a construção do Viaduto Miguel Vicente Cury, obra que ficou marcada como símbolo de modernidade e progresso e também como marco final da implantação do Plano de Melhoramentos Urbanos (BADARÓ, 1996). Apenas em 1971 - com a implementação do Plano Preliminar de Desenvolvimento Integrado - Campinas iria apresentar novas diretrizes para o planejamento urbano do município.

\section{Plano Preliminar de Desenvolvimento Integrado (PPDI) - 1971-1990. Do Plano de Melhoramentos e Embelezamento para o Plano sem Mapa6}

O PPDI (Plano Preliminar de Desenvolvimento Integrado) foi criado no início da década de 1970 durante o mandato do prefeito Orestes Quércia (jan. 1969 - dez. 1972) - em meio a um regime ditatorial - mediante aprovação da lei no 3.960 de 09 de março de 1971. Foi elaborado por uma empresa privada de consultoria em planejamento, a SD consultoria de Planejamento, e teve como financiador o SERFHAU (Serviço Federal de Habitação e Urbanismo), órgão ligado ao BNH (Banco Nacional de Habitação) (PINHO, 2004; RODRIGUES, 2008).

Embora a aprovação do PPDI tenha ocorrido no início da década de 1970, a sua criação remonta aos últimos três anos da década de 1960. No ano de 1967 foi aprovada a lei orgânica dos municípios (Lei no 9.842/67, posteriormente alterada pela Lei Complementar o 09 de 31 de dezembro de 1969), que determinava a criação de um Plano Diretor 7 para os municípios paulistas, cujo nome seria Plano Diretor de Desenvolvimento Integrado (PDDI). Em 07 de junho de 1968, em meio a administração do prefeito Ruy Novaes, foi promulgado o decreto no 3.147, cujo texto assertou a criação do Grupo Executivo do Plano Diretor de Desenvolvimento Integrado (GEPLAN), este, com a finalidade de tomar as rédeas do PPDI (BISNETO, 2009, RODRIGUES, 2008).

Sobre as principais proposições do PPDI, Schneider (2002, p. 22 apud BISNETO,

${ }^{6}$ De acordo com Villaça (2015, p. 221) com o uso desta expressão: “(...) pretende-se designar o novo tipo de plano que a ideologia dominante inventou nas suas constantes tentativas de dar a impressão de que está cuidando do planejamento e "aperfeiçoando-o" continuamente". Esta expressão apresenta tal denominação em função de os mapas terem sido em grande parte dispensados dos planos.
2009, p. 98) afirma que "(...) destacava como questões importantes, o desenvolvimento de um novo eixo de expansão urbana e a ampliação do sistema viário para atender às necessidades do intenso crescimento populacional". Porém, “(...) o plano não se ocupou das áreas periféricas, omitindo-se em relação à região sudoeste, que já na época concentrava o maior contingente de população de baixa renda" (SCHNEIDER, 2002, p. 23 apud BISNETO, 2009, p. 98).

O PPDI foi pautado em três eixos principais que se interligavam: 1) a estratégia de desenvolvimento, que era formada por: “(...) um conjunto de objetivos mais específicos para atuação direta da municipalidade e mais genéricos para aqueles onde o Poder Público Municipal deveria interferir mediante solicitações a outras esferas de poder" (PINHO, 2004); 2) o plano preliminar de estrutura, que foi delimitado para três períodos temporais (1973,1980 e 1990), tencionando a otimização do uso do solo urbano, utilizando como referencial o contingente populacional em cada ano (BISNETO,2009); 3) o plano de ação consistiu em análises e estudos mais minuciosos do processo de otimização do solo urbano proposto no plano preliminar de estrutura (BISNETO, 2009; PINHO, 2004).

O rumo tomado perante as decisões relacionadas ao plano de ação foram fundamentais no sentido de compreender de que forma se deu a expansão urbana, em paralelo à discussão de otimização do uso do solo urbano. Segundo Pinho (2004), este plano foi dividido em três alternativas de desenvolvimento, sendo elas: 1) dispersão industrial e concentração habitacional; 2) concentração industrial e habitacional (800.000 habitantes); 3) dispersão industrial e habitacional (600.000 habitantes) e quatro possíveis tipos de expansão geográfica: Expansão Histórica, Expansão Nordeste-Sudoeste, Expansão para Viracopos e Expansão Norte.

A alternativa escolhida foi a de número 2. Consequentemente a hipótese de expansão geográfica que melhor se enquadrou neste caso foi a Expansão Norte. Segundo Rodrigues (2008, p. 150): "Isso significa dizer que (...) o PPDI-1971 "recomenda" a área norte como a mais adequada para a implantação de um parque industrial, mostrando que se "produz", à força, um vetor de desenvolvimento naquela porção da

${ }^{7} \mathrm{Na}$ prática, não houve qualquer medida de formalização de um Plano Diretor propriamente dito durante o mandato do prefeito Orestes Quércia (BISNETO, 2009) 
cidade". Vale ressaltar que na região norte em 1965 foi instalada a Universidade Estadual de Campinas (UNICAMP) e em 1970 no município de Paulínia - porém, integrada de forma direta com o vetor de desenvolvimento da área norte de Campinas - foi instalada a Refinaria do Planalto (REPLAN), que de acordo com Rodrigues (2008), era responsável naquele momento por um quarto do craqueamento de petróleo no país.

Esta relevante expansão industrial em Campinas, em consonância com um intenso processo de desconcentração industrial que se iniciou em meio à década de 1960 e teve seu auge em meados da década de 1970, propiciou um aumento expressivo do contingente populacional da cidade entre os anos 1970 e 1990. A população partiu de 375.864 habitantes em 1970 para 664.559 em 1980 e 847.595 em 1991, com destaque para a taxa de crescimento populacional durante a década de 1970, que foi de $5,86 \%$ ao ano (RODRIGUES,2008; CAMPINAS, 1998).

Ao longo desse período se desenvolveu uma estrutura social bastante complexa, porém elucidativa do contexto socioeconômico sobre o qual a cidade estabeleceria suas bases dali em diante. De um lado havia uma expressiva demanda de mão-deobra qualificada por parte do mercado de trabalho, que seria então preenchida por profissionais liberais de diversas categorias. Do outro lado houve uma expansão considerável do setor informal, que angariou um significativo contingente populacional de baixa renda, posto além disso que os migrantes possuíam pouca ou nenhuma escolaridade (BAENINGER, 1996).

A partir dos anos 1970 - perdurando por décadas a frente - em meio a um contexto de expressivo crescimento populacional, onde fluxos migratórios ocorriam a todo vapor e a ocupação do solo se intensificava de forma agravante, o acesso à moradia se tornava a cada dia mais dificultoso, consequentemente gerando um processo de favelização cada vez mais explícito (BAENINGER, 1996).

Enveredando pelo mesmo caminho, Rodrigues (2008, p. 196) afirma que: “(...) Campinas foi tomada de assalto pela grave crise econômica dos anos 1980 e surpreendida, ao mesmo tempo, pela força "persistente" dos caudalosos fluxos migratórios que ela atraíra, anteriormente (...)", sendo justamente então "(...) nesse panorama dicotômico de crise econômica e de crescimento demográfico que o Plano Diretor de 1991 se inscreve" (RODRIGUES, 2008, p. 196).
Trata-se de um período onde se iniciariam a aplicação de mudanças substanciais no aparato jurídico, tanto em âmbito municipal, com a promulgação da Lei Orgânica do Município de Campinas, como em âmbito federal, com a promulgação da Constituição Federal de 1988, a fim de propor uma melhor regulamentação das políticas urbanas. O Plano Diretor de 1991 é o marco inicial para a cidade de Campinas, de um período marcado pela grande influência dos planos diretores como modelos fundamentais de planejamento urbano.

\section{Planejamento urbano em Campinas na Nova República. Os planos direto-} res

Conquanto o Brasil tenha ingressado num processo de redemocratização em 1985 após a extinção do regime civil-militar, no que diz respeito ao planejamento urbano, o primeiro Plano Diretor de Campinas foi implantado apenas em 1991, tendo ficado ainda por alguns anos, portanto, sob os auspícios do projeto proposto pelo PPDI.

A década de 1990 se inicia no contexto local com a promulgação da Lei Orgânica do Município de Campinas (LOM), a qual carrega elementos imprescindíveis trazidos pela Constituição Federal de 1988, mais especificamente baseados nos artigos 182 e 183. Segundo Santos (2004), são três os elementos norteadores do planejamento urbano, conforme dispostos pela Constituição Federal de 1988 e incorporados a seguir pela LOM: "(...) o Plano Diretor, os instrumentos de política urbana e os canais institucionais de participação social".

O Plano Diretor de 1991, instituído através da Lei Complementar no 02 de 26 de julho de 1991, foi elaborado por meio da contratação do Arquiteto Siegbert Zanettini, com assessoramento de um grupo denominado de Equipe Técnica do Plano Diretor, composto por profissionais dos mais diversos setores e repartições da administração municipal (CAMPINAS, 2006).

Este plano rompeu com o discurso do urbanismo tecnicista, bastante característico do PPDI. Passou então a pautar a vertente social, intimamente atrelada à questão urbana, além de ter trabalhado a partir de uma abordagem "integrada e global", pretendendo garantir efetividade das políticas de planejamento em meio às influências de um cenário extremamente dinâmico (SILVA, 2010; CAMPINAS, 2006). 
O Plano Diretor de 1991 colocou em destaque elementos que até então sequer haviam sido abordados pelo plano anterior, como as questões ambientais, a descentralização da administração pública e a participação popular, esta que foi bastante incentivada pela criação do Conselho Municipal de Desenvolvimento Urbano (CMDU), órgão que permitiria a participação da sociedade civil nas decisões relacionadas ao planejamento urbano (SILVA, 2010).

Embora o Plano Diretor de 1991 tenha se mostrado bastante promissor e introduzido discussões até então ausentes no plano anterior, o fez apenas de maneira incipiente, não tendo sido capaz de se colocar à altura da complexidade do quadro socioeconômico e urbano local da década de 1990. No texto de introdução do Plano Diretor de 1996 há uma afirmação que serve de diagnóstico do que representou o Plano Diretor de 1991 e ao mesmo tempo de justificativa para implantação urgente do plano seguinte.

O Plano Diretor de Campinas, aprovado pela Lei Complementar $n^{\circ} .2$ de 26/07/91, bem como a Lei Orgânica do município, institucionalizam os princípios que devem reger o desenvolvimento do município e introduzem um conjunto de instrumentos urbanísticos, como o solo criado, o imposto progressivo sobre vazios urbanos e as operações interligadas, prevendo, também, a instituição do Conselho Municipal de Desenvolvimento Urbano - CMDU, como forma de garantir a participação da sociedade no processo de planejamento. Entretanto, as orientações, diretrizes e instrumentos previstos na lei do Plano Diretor têm ainda um nível genérico, exigindo, por isso mesmo, um trabalho de detalhamento que resulte na definição de propostas concretas a serem adotadas para a gestão e o controle do desenvolvimento urbano de Campinas (CAMPINAS, 1996, p.2).

O Plano Diretor de 1996, instituído pela Lei no 04 de 17 de janeiro de 1996, preservou os objetivos fundamentais do plano anterior, em consonância com as proposições sobre a política urbana dispostas na Constituição Federal de 1988. Foi elaborado basicamente pela Secretaria de Planejamento e Meio Ambiente (SEPLAMA), contando apenas com apoio de outras repartições da prefeitura e poucas consultorias externas para a realização de trabalhos específicos (CAMPINAS, 2006).

Desde o início de sua implementação, este plano colocou em prática como eixo principal as políticas urbanas descentralizadas - cuja presença já havia sido notada no plano anterior, porém, até então, apenas como teoria - e os Planos Locais de Gestão Urbana (PLG), elaborados para bairros ou conjunto de bairros, com o intuito de definir normas urbanísticas locais. Neste período foram elaborados três PLG's, o de Barão Geraldo, aprovado pela Lei no 9.199/1996, o da APA (Área de Proteção Ambiental) de Sousas e Joaquim Egídio, aprovado pela Lei no 10.850/2001 e por fim o do Campo Grande, que só seria aprovado na segunda metade dos anos 2000 (CANO; BRANDÃO, 2002; CAMPINAS, 2006).

O Plano de 1996 também foi responsável pela implementação do macrozoneamento de planejamento, que dividiu o município em sete macrozonas, incluindo inclusive as áreas rurais: 1) Macrozona de Proteção Ambiental; 2) Macrozona com Restrição à Urbanização; 3) Macrozona de Urbanização Controlado Norte; 4) Macrozona de Urbanização Consolidada; 5) Macrozona de Recuperação Urbana; 6) Macrozona de Urbanização Controlada Sul e 7) Macrozona imprópria à Urbanização (CANO; BRANDÃO, 2002).

De acordo com Santos (2004): "O Macrozoneamento é o instrumento que define a macro organização do assentamento residencial em face das condições do desenvolvimento socioeconômico e espacial do município".

Ao contrário do Plano Diretor de 1991, o Plano de 1996 abdicou da abordagem de diversas políticas setoriais, como educação, saúde, promoção social, cultura e turismo. Enfatizou as que eram consideradas impulsionadoras da urbanização, particularmente habitação, sistema viário e infraestrutura de saneamento, caracterizando assim uma readesão aos traquejos do urbanismo tecnicista (CANO; BRANDÃO, 2002; CAMPINAS, 2006).

A participação da população no processo de elaboração dos planos, apesar de ter apresentado melhorias em relação ao plano anterior - principalmente se considerado o processo de elaboração dos PLG's - ainda esteve longe de gerar grandes contribuições, tendo ficado restrito à algumas audiências públicas e à presença de integrantes do CMDU, que se fez de maneira pouco efetiva.

Embora o Plano Diretor de 1996 tenha se apresentado bastante promissor, na prática não houve uma confirmação propriamente dita. Conquanto tenha havido um avanço razoável na abordagem de questões até então negligenciadas, este pode ser considerado discreto, tendo em vista o comportamento alarmante de alguns 
dados ao longo dos anos 1990 e início dos anos 2000. Em 1991, 8\% da população do município residia em favelas e/ou ocupações, passando para 9,7\% em 1996 e 16,5\% em 2000 (CANO; BRANDÃO, 2006; CAMPINAS, 1998).

O Plano Diretor de 2006, instituído pela Lei Complementar no 15 de 27 de dezembro de 2006, assumiu as rédeas do planejamento urbano de Campinas após dez anos de vigência do Plano Diretor de 1996, tendo assumido as responsabilidades atribuídas pela Lei no 10.257, de 10 de julho de 2001 (Estatuto da Cidade), que regulamenta os artigos 182 e 183 da Constituição Federal, além de estabelecer diretrizes para a política urbana e outras providências. Da mesma forma que o Plano de 1996, foi elaborado majoritariamente pela Secretaria de Planejamento, tendo contado com a participação de outras secretarias e consultorias realizadas para serviços específicos. Foi coordenado pelo próprio Secretário de Planejamento, Márcio Barbado (SILVA, 2010).

Este plano apresentou nitidamente um caráter revisional, visto que, assumiu as linhas mestras contidas no Plano de 1996. Manteve-se a preocupação com a questão ambiental, bem como com a política de macrozoneamento, porém, foram definidas mais duas macrozonas, totalizando a partir de então nove macrozonas, além de um aperfeiçoamento das já existentes. Consequentemente, os PLG's mantiveram sua participação no planejamento, embora, dessa vez assumindo maior grau de importância após a obrigatoriedade prevista para a elaboração de um PLG para cada macrozona, contido no artigo 19 da Lei Complementar no 15 de 2006. Haviam sido elaborados no plano anterior O PLG de Barão Geraldo, da APA de Campinas e do Campo Grande, porém, este último não havia sido ainda instituído nos termos da lei. No Plano de 2006, todas as macrozonas tiveram seus respectivos PLG's publicados (CAMPINAS, 2006).

No que tange a metodologia de elaboração do Plano Diretor, a política de participação pública continuou sendo pauta, seguindo uma tendência que vinha buscando afirmação desde o Plano Diretor de 1991. Houve uma ampla divulgação e conscientização da população por meio de seções de jornais, banners e e-mails, bem como através do site da Prefeitura Municipal de Campinas. Houve também a participação do Conselho da Cidade de Campinas (CONCIDADE) - instituído em 2005, através de Lei Municipal -, composto por diversos segmentos, como sindicais e as- sociações de moradores, bem como o supracitado CMDU e o Conselho Municipal do Meio Ambiente (Comdema) (SILVA, 2010).

O panorama da dinâmica urbana da cidade de Campinas nos anos 2000 se alterou constantemente, tendo possibilitado ao longo do período pouco ou nenhum otimismo à grande parte da população local, mormente a população de baixa renda. O cenário sócio demográfico suscitou amplas discussões. Conquanto o contingente populacional da cidade tenha sido bastante incrementado ao longo das três décadas anteriores, a taxa de crescimento populacional entre os anos 2000 e 2010 foi de 1,1\% ao ano, ou seja, a menor taxa já registrada desde a década de 1940 (Figura 2). A partir do arrefecimento do aumento do contingente populacional, a expectativa era de que haveria uma melhoria das condições de vida da população, porém, isso não ocorreu na prática.

\begin{tabular}{|l|l|l|}
\hline Ano & População Total & Taxa de Crescimento \\
\hline 1940 & 129.940 & \\
\hline 1950 & 152.547 & 1,61 \\
\hline 1960 & 219.303 & 3,7 \\
\hline 1970 & 375.864 & 5,54 \\
\hline 1980 & 664.559 & 5,86 \\
\hline 1991 & 847.595 & 2,24 \\
\hline 2000 & 969.396 & 1,5 \\
\hline 2010 & 1.080 .113 & 1,1 \\
\hline
\end{tabular}

Figura 2: Taxas de Crescimento Populacional para o Município de Campinas-SP - 1940/2010 Fonte: IBGE - Censos Demográficos de 1940 a 2010

Embora os Planos Diretores de 1991, 1996 e 2006 tenham demonstrado ter um grande potencial no que diz respeito ao cumprimento da função social da cidade e da função social da propriedade - notadamente o Plano de 2006, que foi implementado 5 anos após a promulgação do Estatuto da Cidade - o mesmo não pôde ser atestado na prática. 
Segundo dados do Censo Demográfico de 2010 do IBGE, a população total do município de Campinas era de 1.080.113 habitantes, sendo que 148.278 residiam em aglomerados subnormais ${ }^{8}$, ou seja, aproximadamente $13,7 \%$ da população total, bastante acima dos $6 \%$ correspondentes à escala nacional e pouco distante do pior índice já registrado para o município, de $16,5 \%$ no ano 2000 . Isto está representado no estudo de caso do Bairro Cidade Satélite Íris, localizado na Macrozona 5, que apesar de denominada pelo Plano Diretor de 2006 de Área Prioritária de Requalificação, é um dos territórios mais preteridos no município.

\section{Transformações às margens da Av. John Boyd Dunlop. Do nascimento do} Jardim Campo Grande à transformação em Cidade Satélite Íris

O bairro Cidade Satélite Íris (Figura 3) está localizado na região noroeste da cidade de Campinas, estando inserido na Macrozona $5^{9}$, denominada de Área Prioritária de Requalificação (APR). Esta macrozona está localizada entre a Rodovia dos Bandeirantes e a divisa intermunicipal de Campinas com as cidades de Monte-Mor e Hortolândia, sendo atravessada pelo Rio Capivari e por seu afluente, o Córrego do Piçarrão. A denominação utilizada pelo Plano Diretor de 2006 é bastante pertinente à situação enfrentada pela população residente da área. Consiste em um local com abundante contingente populacional, este, em grande parte pertencente à faixa de baixa renda e frequentemente estabelecido em assentamentos de alto grau de informalidade (CAMPINAS, 2007).

A Lei o 702 de 4 de junho de 1952, bem como as posteriores que alteraram sua redação, concernentes ao plano de arruamento e loteamento do Jardim Campo Grande, foram contemporâneas de um processo emblemático no tocante ao estudo do urbanismo na cidade de Campinas. Naquele momento, o crescimento urbano empreendido em Campinas atingiu níveis alarmantes. A expansão da cidade a partir do final da década de 1940, e principalmente durante a década de 1950, se fez preponderantemente por meio da inclusão de áreas distantes, ausentes de infraestrutura, diferindo, portanto, do processo até então habitual de incorporação de terras

${ }^{8}$ Segundo IBGE (2010) sua definição é a seguinte: “(...) conjunto constituído por 51 ou mais unidades habitacionais caracterizadas por ausência de título de propriedade (...) e pelo menos uma das características a seguir: "irregularidade das vias de circulação e do tamanho e forma dos lotes e/ou carência de serviços públicos essenciais (como coleta de lixo, rede de esgoto, rede de água, energia elétrica e iluminação pública)". adjacentes ao núcleo urbanizado (SEMEGHINI, 1991). Segundo Rodrigues (2008), apenas entre 1951 e 1955 foram aprovados 189 arruamentos e 77.014 loteamentos em Campinas.

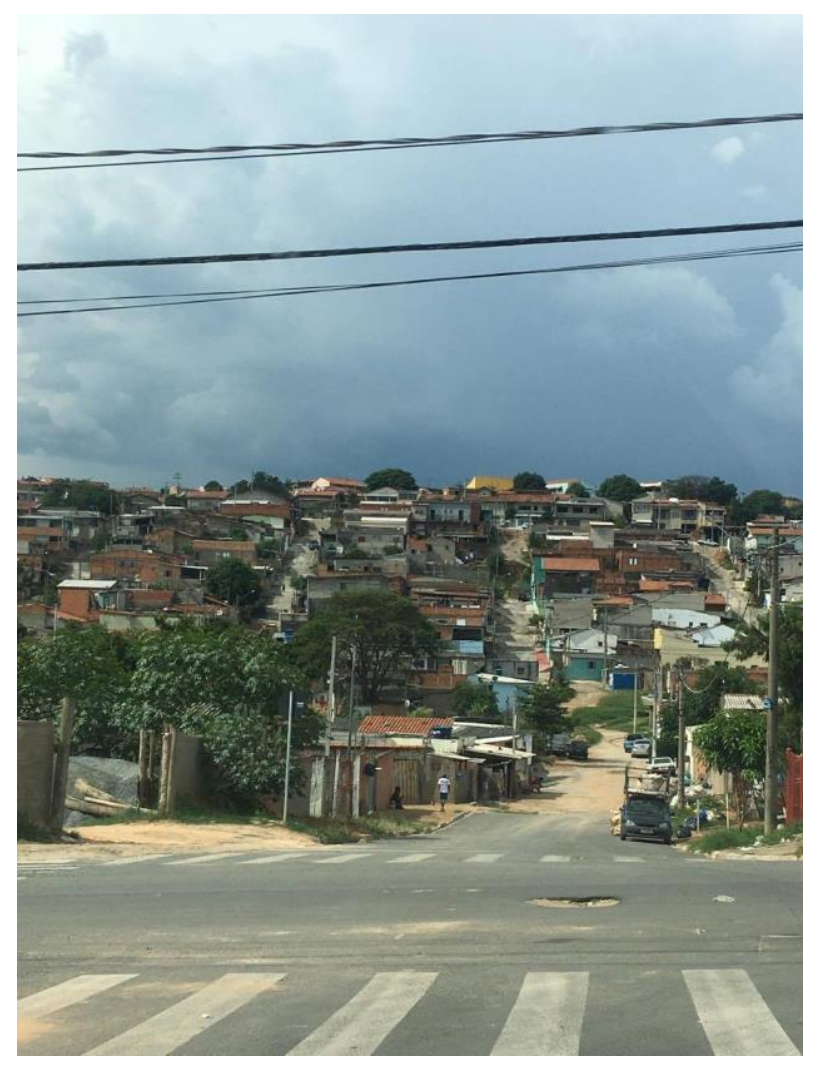

Figura 3: Vista da Rua Maria Neusa Belinteni no bairro Cidade Satélite Íris. Ao fundo predominam ruas de terra e uma grande favela. Fonte: Autoria própria

${ }^{9} \mathrm{~A}$ divisão territorial estabelecida pelo Plano Diretor de 2006 é de 9 macrozonas, que se desdobram em 34 Áreas de Planejamento e 77 Unidades Territoriais Básicas. O objetivo da realização do macrozoneamento segundo Campinas (2006, p. 183) é: “(...) orientar o planejamento das políticas públicas, especialmente aquelas definidoras e/ou indutoras do processo de gestão do território, a partir da compreensão das diferentes realidades das regiões do município, dada sua grande dimensão territorial." 
A área que hoje corresponde ao bairro Cidade Satélite Íris, no momento da aprovação de seu plano de arruamento e loteamento era composta por terras da Fazenda Bela Aliança, de propriedade do Condomínio Jardim Campo Grande. Seu proprietário era Armando do Valle Bastos, presidente da Companhia Agro-Pecuaria e Industrial de Campinas, cuja sede estava instalada na cidade do Rio de Janeiro e uma das filiais encontrava-se estabelecida justamente nas proximidades do bairro $\mathrm{Ci}$ dade Satélite Íris (ARQUIVO MUNICIPAL, 1952).

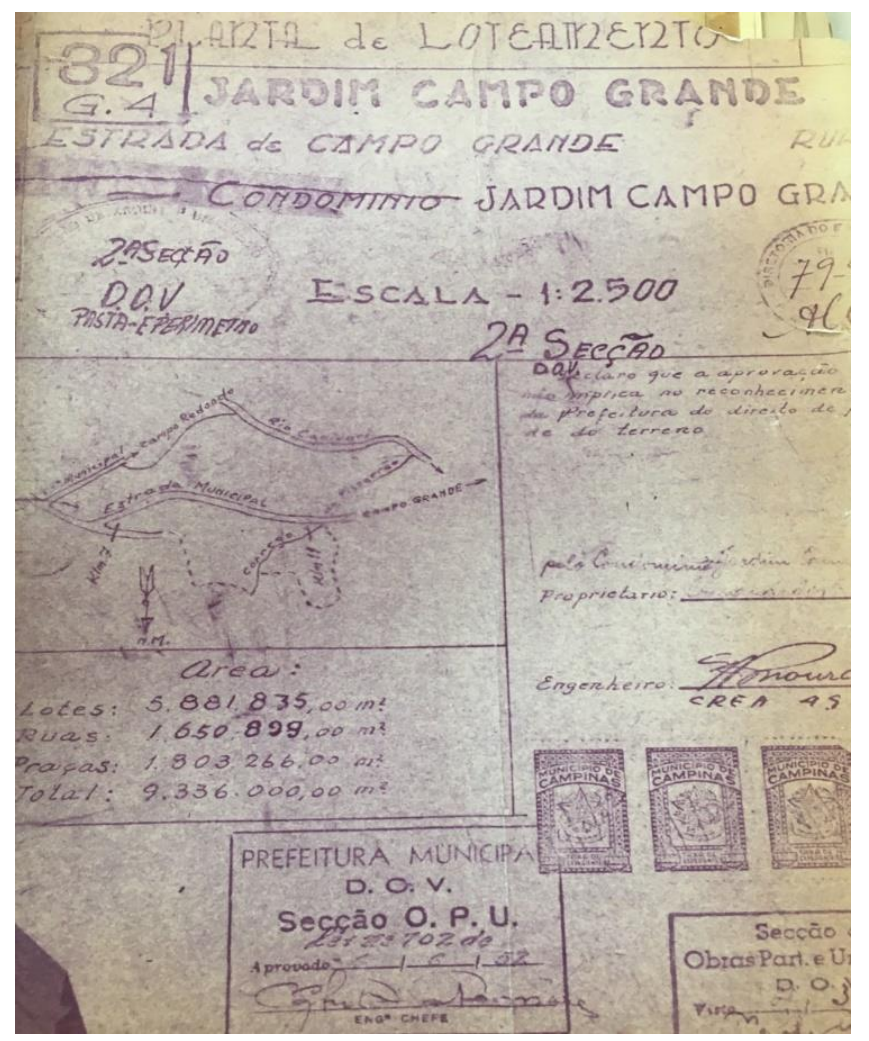

Figura 4: Planta de Loteamento do Jardim Campo Grande - Documento de 16 de junho de 1952. Fonte: Arquivo Municipal de Campinas

${ }^{10}$ Nascido na cidade de São Paulo em 14 de julho de 1893, foi Deputado Federal pelo Estado de São Paulo por três mandatos, entre 1950 e 1963 pelo Partido Social Progressista (PSP), além de diretor-presidente do Banco Popular do Brasil e do banco Cruzeiro do Sul. Somam-se à essas
A propriedade apresentava uma área de $9.336 .000 \mathrm{~m}^{2}$, sendo $5.881 .835 \mathrm{~m}^{2}$, ou, aproximadamente $63 \%$ da área destinada a lotes, sendo $1.803 .266 \mathrm{~m}^{2}$ para praças e $1.650 .899 \mathrm{~m}^{2}$ para ruas (Figura 4). Conforme consta na Lei o 702 de 4 de junho de 1952: "O arruamento é considerado residencial de modo geral", porém, a Lei $\mathrm{n}^{\circ}$ 1617 de 1956 altera sua redação e afirma o seguinte: "O arruamento é considerado misto". Uma possível explicação se dá em torno da questão do comércio, que até então era restrito à apenas algumas quadras, bastante incipiente, e a partir de então passa a se expandir e se espalhar em diferentes núcleos no interior do bairro (ARQUIVO MUNICIPAL, 1982).

Uma parte do loteamento foi comercializada inicialmente pelo próprio Condomínio Jardim Campo Grande, e o restante vendido para os Irmãos Spina (Miguel Spina, Francisco Paulo Spina, Nicolino Spina e Paschoal Spina), estes, proprietários das Indústrias Reunidas Irmãos Spina (I.R.I.S.), para Carmelo D’Agostino ${ }^{10}$ e para a empresa Civitas - Companhia Imobiliária dos Bons Negócios S.A (ARQUIVO MUNICIPAL, 1982).

Curiosamente, o nome "Íris", que faz parte do nome Cidade Satélite Íris, que substituiu a denominação de Jardim Campo Grande, é uma referência à abreviação do nome do grupo empresarial pertencente aos Irmãos Spina, as Indústrias Reunidas Irmãos Spina. Estes, eram filhos de imigrantes italianos, que aportaram na cidade de São Paulo por volta do ano de 1890 (GABRIEL, 2004).

As Indústrias Reunidas Irmãos Spina começaram como uma empresa de pequeno porte, fundada em 1924, instalada no bairro do Bom Retiro, sob a alcunha de "Graphico Irmãos Spina”. Se tornaram conhecidos por terem sido pioneiros na produção de cadernos com espiral de arame no Brasil, porém, também realizavam serviços de impressão. Nas décadas seguintes se desenvolveram até dar origem ao Grupo Spina, ou propriamente Indústrias Reunidas Irmãos Spina, se tornando o maior complexo papeleiro da América Latina. Possuíam fábricas nos bairros do Brás e do Limão na cidade de São Paulo, nos municípios de São Roque no Estado de São Paulo e em Petrópolis no Estado do Rio de Janeiro (GABRIEL, 2004).

funções os cargos de Presidente do Centro de Debates de Assuntos Econômicos, da Assembleia do Centro de Debates Cásper Líbero, bem como a autoria de diversas obras na área da economia (CPDOC, 2017). 
Sobre os ramos de atuação das I.R.I.S. expõe Gabriel (2004): "Suas atividades abrangeram o plantio de eucalipto em suas empresas reflorestadoras estrategicamente distribuídas nos municípios vizinhos de São Paulo, passando pela fabricação de celulose, papel e culminando com a manufatura gráfica e metalúrgica". Considerando que o uso da terra na Região do Campo Grande na década de 1960 era essencialmente destinado a pastagens e reflorestamento com Eucaliptus e Pinus, está delimitado então um forte indício do motivo da escolha dos industriais paulistanos em investir nos loteamentos neste local (CAMPINAS, 2012).

Porém, em 1973, os Irmãos Spina cederam sua parte à Empresa Investimentos Campinas Ltda. Em 1979 o mesmo foi feito por parte da Civitas Companhia Imobiliária dos Bons Negócios, bem como com os espólios dos falecidos Carmelo D’Agostino e sua herdeira Amélia Biondi D'Agostino. A Empresa Investimentos Campinas passou a deter então $100 \%$ dos lotes remanescentes não comercializados (ARQUIVO MUNICIPAL, 1982).

Na década de 1970, o PPDI previa para a área do loteamento Cidade Satélite Íris uma intensificação nas ocupações tanto residenciais quanto industriais. Isto de certa maneira ocorreu, porém, sem qualquer tipo de ordenamento. A população da Região do Campo Grande no início da década de 1970 era de 1.000 habitantes, passando a ter no início da década de 1980 mais de 32.000 habitantes. Soma-se ao intenso processo de ocupação da região uma total ausência de infraestrutura, o que viria a escancarar aos poucos a negligência por parte do Poder Público Municipal, em conformação com a consolidação de um cenário local caótico (SILVA, 2013; CAMPINAS, 2012).

Um exemplo bastante elucidativo deste cenário foi a implantação do "Lixão da Pirelli ${ }^{11 "}$, no ano de 1972, em uma área de 42 hectares no bairro Cidade Satélite Íris. Foram despejados neste local não somente o lixo doméstico de toda a cidade, mas também lixo industrial e hospitalar. O lixão foi desativado pela prefeitura em 1984, porém, permaneceu por mais de uma década recebendo dejetos de todos os tipos (CAMPINAS, 2007).

${ }^{11}$ Recebeu essa denominação em função da proximidade com as Indústrias Pirelli, inaugurada em 1953 sob o nome de Dunlop do Brasil S. A. Indústria de Borracha.
Não bastassem os problemas ambientais oriundos do funcionamento do lixão, como a contaminação do solo e dos corpos hídricos, a área do lixão, tanto no seu entorno quanto na parte interna passou a ser local de estabelecimento da população de baixa renda (Figura 5 ).

Irani Piffer [membra da Associação de Moradores e da Comunidade São Francisco] lembra que, para cobrir o lixo, "a própria pessoa colocava a terra, tudo. Mas, com o passar do tempo, você ia fazer uma visita na casa da pessoa e via ainda saquinho plástico subindo do chão. [...] Quando as crianças furavam o pé, às vezes, a gente ia fazer uma visitinha e ela estava lá com o pé furado por seringa, agulha de seringa" (ROLDÃO, 2011, p. 72).

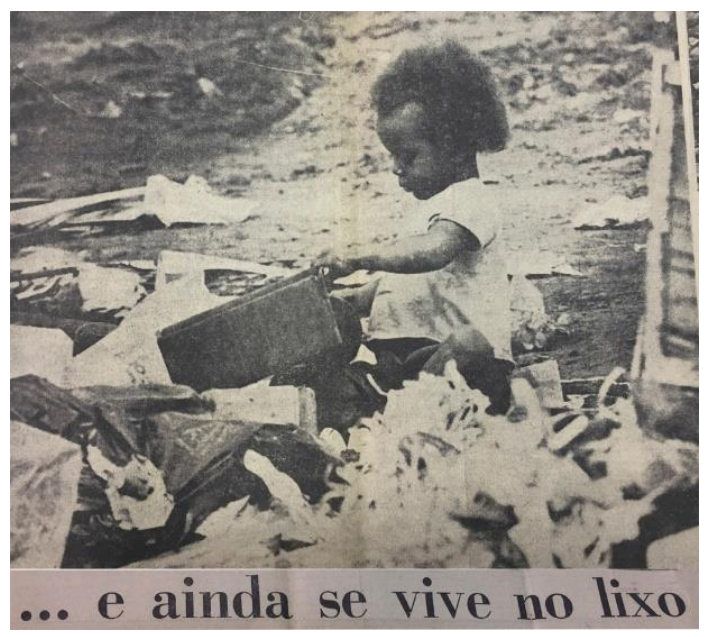

Figura 5: Recorte de matéria do Jornal "O Diário do Povo" de 13 de setembro de 1979 sobre a vida da população na área do Lixão da Pirelli. Fonte: Jornal Diário do Povo - Hemeroteca da Biblioteca Pública Municipal Prof. Ernesto Manoel Zink

Segundo Roldão (2011), em 1984 - ano em que o lixão viria a ser desativado houve diversas inspeções do Departamento de Limpeza Pública da Prefeitura, tendo sido constatadas a presença de uma criação de suínos, um matadouro 
clandestino, bem como cerca de 700 catadores de lixo, que garantiam sua renda em função da coleta de material reciclável. Relatos de moradores e transeuntes apontavam ainda casos drásticos, em que era possível observar pessoas retirando restos de alimentos do lixão, não mais para alimentar os porcos como era bastante frequente, mas, ao contrário, para o próprio sustento.

Diante deste cenário, que se apresentava não apenas no bairro Cidade Satélite íris, mas na Região do Campo Grande como um todo - o qual esteve presente desde o início da década de 1970 - quem fez as vezes do Poder Público Municipal foi a Igreja Católica, por intermédio das Comunidades Eclesiais de Base (CEB's) ${ }^{12}$, contando com a participação não menos importante de diversos sindicatos, movimentos sociais e associações de bairro (ROLDÃO, 2011).

O próprio caso do Lixão da Pirelli em si é bastante elucidativo do que representou a atuação das CEB's na região. Padre Benedito Ferraro, líder da rede de comunidades pertencentes à Região do Campo Grande durante quase uma década, instalou no Satélite Íris uma dessas comunidades, logo que visualizou tamanha agudez das mazelas vividas pela população, esta, amotinada pela presença do lixão. Além dos ritos religiosos inerentes à sua função, Padre Ferraro - em conjunto com seminaristas - foi responsável por um amplo processo de conscientização da população a respeito dos possíveis problemas causados pelo contato com o lixão, bem como serviu de interlocutor entre a população e a Prefeitura Municipal. Em alguns casos, até mesmo financeiramente a comunidade foi auxiliada (ROLDÃO, 2011).

No que tange a esfera legal à qual se vinculava o bairro Cidade Satélite Íris, desde a lei $\mathrm{n}^{\circ} 1.617$ de 12 de outubro de 1956, até meados da década de 1990, quando se deu início de fato ao período de instituição dos Planos Diretores, nenhuma alteração substancial foi promulgada pelo Poder Público Municipal. Sequer as leis existentes, tiveram suas diretrizes respeitadas.

\section{Considerações finais}

As discussões realizadas ao longo do presente artigo intencionavam provocar uma reflexão sobre como as políticas de planejamento urbano engendradas pelo Poder

${ }^{12}$ Segundo Dornelas (2006): "As Comunidades Eclesiais de Base (CEBs) surgiram no Brasil como um meio de evangelização que respondesse aos desafios de uma prática libertária no contexto
Público Municipal contribuíram para a produção do espaço urbano, tomando como estudo o caso do Cidade Satélite Íris. Para tal intento, deve-se recordar alguns elementos contextuais presentes nas políticas públicas na metade do século $\mathrm{XX}$, especialmente dentro dos Planos Diretores Municipais. Durante a década de 1950 esteve em vigência o Código de Construções de 1934, que seria então incorporado ao Ato $\mathrm{n}^{\circ} 118$ de 1938, que instituiu o Plano de Melhoramentos Urbanos de Prestes Maia. Este, que era limitado às normas viárias e de parcelamento de quadras, consequentemente se fez ausente na estipulação de obrigações aos loteadores, tendo promovido uma expansão horizontal do solo urbano sem precedentes. Embora tenha sido aprovada, em 1953 uma alteração na legislação, exigindo a maior reserva de áreas livres e outra em 1957, que atribuía ao loteador a responsabilidade de executar as redes de água, em nada seria alterado o cenário referente ao bairro Cidade Satélite Íris (BADARÓ, 1996).

Nitidamente o que se observou foi um processo de fiscalização bastante limitado, restrito essencialmente à área central e aos bairros contíguos. Este comportamento é esclarecedor de um momento cujas práticas visavam a revalorização da região central, em consonância com o fortalecimento do capital imobiliário e um processo de verticalização em franca ascensão, no entanto, no que diz respeito à expansão descabida de loteamentos, as medidas foram importantes, tendo demonstrado um claro arrefecimento deste processo (BADARÓ, 1996).

A partir de 1971, quando da aprovação do PPDI, até 1991, momento de instituição do primeiro Plano Diretor do município, as políticas urbanas locais foram marcadas pelo predomínio notório de uma ótica tecnicista, onde, em uma suposta escala de consentimentos, estiveram presentes apenas a elite política local e os representantes do capital imobiliário (KOTHER; FERREIRA; BREGATTO, 2006).

Durante esse período - porém, não apenas neste - foram recorrentes os apelos da população local, relacionados aos mais diversos temas. Representantes de associações de bairro e de movimentos sociais mantiveram comunicação frequente com a prefeitura. Constata-se neste momento de forma explícita as consequências da prática do toma lá dá cá entre loteadores e a Prefeitura Municipal. Os loteadores

sociopolítico dos anos da ditadura militar e, ao mesmo tempo, como uma forma de adequar as estruturas da Igreja às resoluções pastorais do Concílio Vaticano II, realizado de 1962 a 1965". 
nunca realizaram as obras de melhoramentos públicos que eram de sua responsabilidade. Além de não haverem sido alvos de fiscalização, passaram a ser amparados ainda pela legislação municipal, que após um determinado período de tempo, prescrevia estas obras, e estas passavam a ser de responsabilidade da municipalidade. Eis que o Poder Público Municipal também não fez cumprir suas obrigações, consequentemente, repassando o ônus à própria população, já bastante prejudicada pelas condições de vida.

O período que vem logo em seguida, partindo de 1991, composto de três planos diretores, suscitou muitas expectativas. O Plano Diretor de 1991, contanto tenha sido instituído em um contexto de redemocratização do país, de surgimento de uma nova Constituição, e tenha abordado temas até então negligenciados pelas gestões anteriores, como a questão ambiental e a participação popular, se mostrou bastante distante da práxis. Embora o bairro Cidade Satélite Íris viesse a ser mencionado com mais frequência pelo Poder Público Municipal e estivesse nas pautas de discussão do Plano Diretor, muito pouco foi feito considerando o legado negativo acumulado ao longo das décadas anteriores e o contexto da década de 1990 que escancarava um quadro urbano e socioeconômico extremamente delicado.

A aprovação do Plano Diretor de 1996 demonstrou avanços mais significativos, porém, ainda discretos. A política de macrozoneamento instituída, incluiu o Satélite Íris na Macrozona 5, denominada de Área de Recuperação Urbana, tendo sido sempre colocada - ao menos na teoria - como área prioritária. No mesmo contexto, começaram a ser elaborados os PLG's. Neste primeiro momento foram três, o da APA de Campinas, composta pelos distritos de Sousas e Joaquim Egídio, o de Barão Geraldo e por fim o do Campo Grande, porém, o último, apesar de elaborado não chegou a ser aprovado, tendo atingido êxito apenas em 2004, já beirando a aprovação de um novo plano diretor.

O Plano Diretor de 2006 apresentou um caráter revisional, com uma discussão mais ampla e aperfeiçoada em torno das macrozonas. A Macrozona 5 passou a ser denominada de Área Prioritária de Requalificação. Diversas ações continuaram ano após ano a serem planejadas, porém, o que se nota é que os problemas sociais presentes no local estudado, ao invés de atenuados, foram agravados, e sequer dão sinais de trégua.

Em suma, o planejamento urbano atuante no Brasil, seja em escala estadual, regional ou local, apresenta-se sobretudo como discurso. Os planos de ordenamento urbano elaborados ao longo das últimas décadas, ao invés de servirem como guia para a ação do Estado, pautados na esfera das políticas públicas, serviram meramente como um suporte ideológico a serviço das classes dominantes, a fim de acobertar os problemas de grande parte da população urbana, em função de seus interesses (VILLAÇA, 2015).

\section{Referências}

ARQUIVO MUNICIPAL. Ao D.O.V: Civitas Companhia Imobiliária dos Bons Negócios. São Paulo: 1963.

Histórico. Empresa Investimentos Campinas LTDA. Campinas: 1982.

$2 p$.

IIImo Sr. Diretor da D.O.V da Prefeitura de Campinas. Companhia Agro-Pecuaria e Industrial de Campinas. Campinas: 12 de dez. 1952.

BADARÓ, Ricardo. Campinas: O despertar da modernidade. Campinas: Centro de Memória Unicamp, 1996. 161 p.

BAENINGER, Rosana. Espaço e tempo em Campinas: migrantes e a expansão do pólo industrial paulista. Campinas: Centro de Memória Unicamp, 1996. 148p.

BATTISTONI FILHO, Duílio. Campinas: Uma visão histórica. Campinas: Pontes, 1996. $79 \mathrm{p}$.

BISNETO, Victor Begeres. Formação territorial e planejamento urbano: por um uso mais solidário do território de Campinas/SP. 2009. 199 f. Dissertação (Mestrado) - Faculdade de Filosofia, Letras e Ciências Humanas, Departamento de Geografia, Universidade de São Paulo, São Paulo, 2009. Disponível em: $<$ http://www.teses.usp.br/teses/disponiveis/8/8136/tde-30112009-122131/ptbr.php>. Acesso em: 21 out. 2017.

CAMPINAS. Prefeitura Municipal de Campinas. Secretaria de Planejamento e Desenvolvimento Urbano. Sumário de dados: população de Campinas e região. Campinas: 1998. 105p. Disponível em: <http://www.campinas.sp.gov.br/governo/seplama/publicacoes/sumario-dados-demograficos.php >. Acesso em: 20 out. 2017. 
Prefeitura Municipal de Campinas. Plano Diretor de Campinas 2006. Campinas: SEPLAMA/PMC, 2006. 476p.

Prefeitura Municipal de Campinas. Plano Diretor de Campinas 1996. Campinas: SEPLAMA/PMC, 1996. 303 p.

Prefeitura Municipal de Campinas. Plano Local de Gestão Urbana: Macrozona 5. SEPLAMA: 2007.

. Prefeitura Municipal de Campinas. Secretaria Municipal de Meio-Ambiente. Unidade de Conservação de Proteção Integral: Parque Natural Municipal do Campo Grande - Caderno de Subsídios. Campinas: Secretaria Municipal de Meio Ambiente, 2012. 33p. Disponível em: ～<http://www.campinas.sp.gov.br/governo/meio-ambiente/conservacao-da-natureza.php>. Acesso em: 10 nov. 2017.

CANO, Wilson. Desequilíbrios regionais e concentração industrial no Brasil 1930/1970. 1981. 447 f. Tese (Livre-Docência) - Instituto de Filosofia e Ciências Humanas, Departamento de Economia e Planejamento Econômico, Universidade Estadual de Campinas, Campinas, 1981.

CANO, Wilson; BRANDÃO, Carlos A. (Org.). A Região Metropolitana de Campinas: urbanização, economia, finanças e meio ambiente. Campinas: Editora Unicamp, 2002. $2 \mathrm{v}$.

CARPINTERO, Antonio Carlos C. Momento de ruptura: as transformações no centro de Campinas na década dos cinquenta. Campinas: Centro de Memória Unicamp, 1996. $91 \mathrm{p}$.

CARVALHO, Edemir de. Crise urbana e habitação popular em Campinas: 18701956. 1991. 108 f. Dissertação (Mestrado) - Instituto de Filosofia e Ciências Humanas, Departamento de Ciências Sociais, Universidade Estadual de Campinas, Campinas, 1991.

CPDOC (Rio de Janeiro). Fundação Getúlio Vargas. Verbete: D'AGOSTINO, Carmelo. Disponível em: <http://www.fgv.br/cpdoc/acervo/dicionarios/verbete-biografico/d-agostino-carmelo>. Acesso em: 26 nov. 2017.
DORNELAS, Nelito Nonato. A identidade das CEBs. Vida Pastoral, São Paulo, ano 47, n. 248 1, p.3-5, jun. 2006. Bimestral. Disponível em: <http://www.vidapastoral.com.br/artigos/eclesiologia/a-identidade-das-cebs/>. Acesso em: 28 out. 2017.

GABRIEL, Eliseu. Projeto de Lei 01-0408/2004: justificativa. São Paulo: 2004. Disponível em: <http://cmspbdoc.inf.br/iah/fulltext/justificativa/JPL0408-2004.pdf>. Acesso em: 25 out. 2016

IBGE. (Org.). Aglomerados Subnormais: Informações Territoriais. 2010. Disponível em: <https://ww2.ibge.gov.br/home/presidencia/noticias/imprensa/ppts/00000015164811202013480105748802.pdf>. Acesso em: 08 fev. 2018.

KOTHER, M. B. M.; FERREIRA, Mário dos Santos; BREGATTO, P. R. (Org.). Arquitetura e urbanismo: posturas, tendências e reflexões. Porto Alegre: Edipucrs, 2006. $390 p$

KROGH, Daniela da Silva Santos; SALGADO, Ivone. Anhaia Mello e sua contribuição para a difusão do urbanismo norte-americano: o debate urbanístico na cidade de Campinas na década de 1930. In: IV ENCONTRO DA ASSOCIAĊÃO NACIONAL DE PESQUISA E PÓS-GRADUAÇÃO EM ARQUITETURA E URBANISMO, 2016, Porto Alegre. Anais...: Porto Alegre: Anparq, 2016. p. 1 - 18. Disponível em: <http://www.anparq.org.br/enanparq-IV.php>. Acesso em: 13 out. 2017.

LAPA, José Roberto do Amaral. A cidade: Os cantos e os antros. Campinas: Unicamp/Edusp, 1996. 368 p.

MARTINS, Valter. Cidade-laboratório: Campinas e a febre amarela na aurora republicana. História, Ciências, Saúde - Manguinhos, Rio de Janeiro, v.22, n.2, abr.jun. 2015, p.507-524. Disponível em: <http://www.scielo.br/scielo.php?script=sci_issuetoc\&pid=0104-597020150002\&lng=pt\&nrm=isso >. Acesso em: 30 set. 2017.

NUNES, E. D.; PAVANATI, C. M. A atuação da Comissão Sanitária de Campinas-SP: ações de polícia médica durante a primeira república. Revista de História Regional, Ponta Grossa, v. 21, n. 1, p. 222-247, 2016. Disponível em: <http://www.revistas2.uepg.br/index.php/rhr>. Acesso em: 29 set. 2017. 
PAVANATI, Cássia Mariane. A saúde e a doença em Campinas: 1889-1930 (re) visitando uma história. 2013. 88 f. Dissertação (Mestrado) - Saúde Coletiva - Faculdade de Ciências Médicas, Universidade Estadual de Campinas, Campinas, 2013.

PINHO, Antônio José de. PPDI - Plano Preliminar de Desenvolvimento Integrado de Campinas elaborado entre os anos de 1969 e 1970: depoimento proferido por Antônio José de Pinho. 2004. Disponível em: <http://www.saude.campinas.sp.gov.br/seplan/eventos/camp230/camp2302semipal1.htm>. Acesso em: 19 out. 2017.

RODRIGUES, Fabíola. A invenção da cidade: população e planejamento urbano, imaginário e poder na formação urbana de Campinas (1930-2006). 2008. 363 f. Tese (Doutorado) - Instituto de Filosofia e Ciências Humanas, Departamento de Demografia, Universidade Estadual de Campinas, Campinas, 2008.

ROLDÃO, Ivete Cardoso do Carmo (Org.). Memórias do Campo Grande: uma história de lutas e religiosidade às margens da John Boyd Dunlop. Aparecida: Santuário, 2011. $140 \mathrm{p}$.

SANTOS, Sarah M. M. dos. Campinas nos anos 90: perspectivas e realidade. 2004. Disponível em:<http://www.saude.campinas.sp.gov.br/seplan/eventos/camp230/camp2303semipal3.htm>. Acesso em: 25 out. 2017.

SCHNEIDER, Ingrid Elizabeth. Confrontos e dificuldades na implementação dos instrumentos urbanísticos propostos nos Planos Diretores Municipais de Campinas na década de 90. 2002. Dissertação (Mestrado) - Faculdade de Arquitetura e Urbanismo, Universidade de São Paulo, São Paulo, 2002.

SEMEGHINI, Ulysses Cidade. Campinas (1860-1980): Agricultura, industrialização e urbanização. 1988. 282 f. Dissertação (Mestrado) - Instituto de Economia, Universidade Estadual de Campinas, Campinas, 1988.

. Do café à indústria: uma cidade e seu tempo. Campinas: Editora Unicamp, 1991. $197 \mathrm{p}$.
SILVA, Maittí Gadioli Monteiro da. Participação popular no município de Campinas: avaliação do processo de elaboração do plano local da macrozona 05. 2010. 169 f. Dissertação (Mestrado) - Centro de Ciências Exatas, Ambientais e Tecnológicas, Pontifícia Universidade Católica de Campinas, Campinas, 2010. Disponível em: <http://www.bibliotecadigital.puc-campinas.edu.br/tde_busca/>. Acesso em: 29 out. 2017.

SILVA, Ricardo Alexandre da. 0 processo de expansão urbana recente da região sudoeste de Campinas: agentes e impactos. 2013. 131 f. Dissertação (Mestrado) - Centro de Ciências Exatas, Ambientais e Tecnológicas, Pontifícia Universidade Católica de Campinas, Campinas, 2013. Disponível em: <http://www.bibliotecadigital.puc-campinas.edu.br/tde_busca/>. Acesso em: 02 nov. 2017.

VILLAÇA, Flávio. Uma contribuição para a história do planejamento urbano no Brasil. In: DEÁK, Csaba; SCHIFFER, Sueli Ramos (Org.). O processo de urbanização no Brasil. 2. ed. São: Edusp, 2015. Cap. 6. p. 169-243. 